\title{
Social Responsibility in Sports: Current Landscape
}

\author{
Brendan Parent*
}

\begin{abstract}
While most industries are being held increasingly responsible for engaging in socially responsible business practices and contributing to public interest efforts, professional sports are likely held to an even higher standard of what is traditionally considered corporate social responsibility (CSR). Professional sports are intricately embedded in their communities, arguably more dependent on consumer and government support, with greater influence on culture and more power to improve community well-being. These facts lead to the expectation that professional sports will contribute more to society than just exciting exhibitions. As this expectation is relatively new, the parameters of social responsibility in sports (SRS) is not well defined. Most professional leagues and teams in the United States are participating in efforts to improve their communities, the well-being of their employees, and promote safety and integrity within their competitions. But neither the motivations behind these efforts nor the outcomes have been well characterized. This examination draws on original research to describe how SRS differs from typical CSR. It will then identify some key legal mechanisms through which socially responsible efforts in sports are carried out, and the importance of a leadership culture that embraces SRS. Finally, it will explain the value of authentic social responsibility efforts, both to the community and to the implementing sport organization, which calls for investments in SRS initiatives that are strategically tailored to the organization's identity and are held accountable for meeting the needs of the community.
\end{abstract}

\section{Introduction}

This paper seeks to describe the current landscape of social responsibility efforts in sports (hereafter SRS) undertaken by various professional North American sports leagues, teams, and related entities. Most industries are being held increasingly responsible for engaging in honest, environment- and healthforward business practices, and for contributing to external social improvement efforts. Professional sports are intricately embedded in their communities,

\footnotetext{
* Brendan Parent, JD, is director of Sports and Society, director of Applied Health at New York University's (NYU) School of Professional Studies, and a faculty affiliate of the Division of Medical Ethics at NYU Langone Medical Center; email: brendan.parent@nyu.edu

The author would like to thank Kostya Kennedy and Sam Marchiano for their invaluable contributions to the research on which much of this paper is based, and for their commitments to the social responsibility of sports.
} 
arguably more dependent on consumer and government support, with greater influence on culture and more power to improve community well-being.

This examination draws on interviews with SRS leadership of several U.S. professional sport organizations, focus groups with diverse sports fans, and an international survey poll. Aided by this research, it will first describe how SRS differs from typical corporate social responsibility (hereafter CSR). It will then identify some key legal mechanisms through which socially responsible efforts in sports are carried out, and the importance of a leadership culture that embraces SRS. Finally, it will explain the value of authentic social responsibility efforts, both to the community and to the implementing sport organization, which calls for investments in SRS initiatives that are strategically tailored to the organization's identity and are held accountable for meeting the needs of the community.

\section{Differences Between SRS and CSR}

SRS is distinct from, and arguably more powerful than, CSR in other industries due to four main factors: (1) passion, (2) economics, (3) transparency, and (4) stakeholder management. ${ }^{1}$ Embracing these differences might help maximize the impact of professional sports' social responsibility programs.

\section{Passion}

The level of passion that sports generate is unique in the marketplace. Sports fans identify as members of the team community, if not as members of the team itself, and express deep connection with their team "brands." Contemporary research holds that sports affect socialization and psychology on both individual and collective levels. ${ }^{2}$ On an individual level, sports feed the fan's core self-assessment and identity while on a collective level sports allow members of society to cut across social strata (e.g., race, income, gender) in order to experience a common outlet. Sports are a core component of community and identity in ways that other industries are not, and thus have the power to shape the lives of everyone within the community, including those who are vulnerable and disadvantaged. This power is part of the basis of sports' responsibility to society.

Teams also represent their host cities, and are often among the most powerful entities within the city. In focus groups, fans expressed the belief that their teams' successes are contingent on fan contributions and loyalty, thus the teams and athletes should give back to the community. ${ }^{3}$ Accordingly, city residents might come to expect some representation and protection from its sports teams somewhat akin to what they expect from their city government.

\footnotetext{
See Kathy Babiak \& Richard Wolfe, Determinants of Corporate Social Responsibility in Professional Sport: Internal and External Factors, 23 Journal of SpORT MANAGEMEnT 717, 722-23 (2009). https://doi.org/10.1123/jsm.23.6.717

2 See Daniel Wann, Michael Schrader, \& Anthony Wilsen, Sport Fan Motivation: Questionnaire Validation, Comparisons by Sport, and Relationship to Athletic Motivation, 22 Journal of Sport BEHAVIOR 1, 1999.

3 NYU Focus Groups hosted by Fondulas Strategic Research, LLC, Jan. 13, 2016, Chicago, Illinois. Transcripts on file with authors.
} 


\section{Economics}

Sports economics extend far beyond direct event and merchandise sales to television deals as well as key public investment in the form of infrastructure and related development. Given the visibility and power of sports, its economics tend to be less strictly market dependent and depend more on close ties between leagues, teams, and host cities, and close cooperation between civic leaders and team management and players. Sports venues host paid public gatherings like concerts and graduations, they can help revitalize local economies or displace previously existing housing and businesses, and they can provide refuge from danger like terrorism and environmental disaster. This further embeds professional sports into the fabric of their host cities, endowing them with responsibility in situations of need.

\section{Stakeholder Management}

Sports leagues are uncommonly dependent on stakeholder management. While large conglomerates in other industries may be able to exercise a degree of control over all aspects of production, sports leagues cannot provide a finished product without the close cooperation of numerous stakeholders including, but not limited to, players, individual teams, media, fans, and sponsors. As noted by a prominent leader of a professional league's social responsibility efforts:

Social responsibility for us has been not just the work we've been doing with our community partners, but demonstrating who we stand for reputationally and as a business matter with both our for-profit business partners and our non-profit business partners as well as our key stakeholders, our players, our teams, our owners, and very significantly, our employees. ${ }^{4}$

The success of many league-led social responsibility efforts depends on cooperation from teams and athletes.

\section{Transparency}

The visibility of sports creates expectations for transparency uncommon in other industries. Information about many aspects of the sports industry is widely accessible. Team and athlete outcomes are constantly monitored and advertised. Personnel decisions such as player salaries, movement, and usage are often announced through public statements and press conferences to generate buzz and public engagement. Off-the-court/field behavior of athletes and other high-level sports employees - positive and negative-is subject to much greater public attention than the behavior of employees in other industries. It is likely that fans, media, industry partners, and public interest partners all subject social responsibility programs in sports to greater accountability.

For these reasons, the sports industry faces distinct challenges that affect successful implementation of social responsibility programs. It is thus important

\footnotetext{
4 NYU Professional League Interview No. 1, 2016. Transcripts on file with authors.
} 
to examine why these programs are worth the effort, and how best to implement them.

\section{Setting the Stage for SRS: Legal Developments and Leadership}

\section{Governmental Pressure}

The principle of social responsibility flows from the idea that those with power should help those in need. All ethical frameworks espouse some version of this principle, and all functioning communities rely in part on this premise. While the law in the US avoids setting requirements or standards for being a morally and socially responsible citizen, it does set thresholds to prevent socially irresponsible behavior. For example, states require that sports leagues and teams conduct themselves in a manner consistent with statutory rights, particularly as it relates to values such as diversity and equal opportunity.

This scrutiny is apparent in cases relating to ensuring equal protection for minorities and promoting diversity. For instance, in 2013, the New York Attorney General (NYAG), Eric Schneiderman, proactively opened an inquiry into reports that three National Football League (NFL) draft prospects may have been asked questions related to sexual orientation during the annual Scouting Combine held in Indianapolis. ${ }^{5}$ In an official letter to NFL Commissioner Roger Goodell, Schneiderman pointed to specific reports that prospective draftees were asked "whether they have a girlfriend, are married, or like girls." Citing New York State Human Rights Law, N.Y. Executive Law s. 296, Schneiderman noted that it was illegal for any company conducting business in the State of New York to discriminate against present and prospective workers based on sexual orientation. ${ }^{7}$ Citing the fact that 20 of 32 teams are located in jurisdictions with similar laws and that such questions regarding sexual orientation were also a violation of the 2011 NFL Players Association collective bargaining agreement (CBA), the NYAG reiterated that "[e]qual protection under the law is an essential issue for employers, employees, and prospective job applicants." "In the end, the NYAG compelled the NFL to meet and the NFL had to commit to reinforcing policies against discrimination based on sexual orientation, prominently displaying such policies, conducting training across the league around the policy, and distributing the updated policy to all 32 teams. $^{9}$

\footnotetext{
NYAG Eric Schneiderman, Re: Sexual Orientation Non Discrimination, letter to NFL Commissioner Roger Goodell, March 14, 2013. Available at http://www.ag.ny.gov/pdfs/NFL_Final.pdf.

6 Id.

7 Id.

8 Id

9 Office of NYAG, A.G. Schneiderman Announces Agreement With National Football League to Strengthen Policies Against Discrimination Based on Sexual Orientation, Press Release (April 24, 2013). Available at http://www.ag.ny.gov/press-release/ag-schneiderman-announcesagreement-national-football-league-strengthen-policies
} 
As highly visible institutions, sports leagues and teams are generally aware that they can be subject to governmental scrutiny. Leagues and teams promoting certain kinds of internal social responsibility efforts, like training to guide personnel behavior, helps ensure compliance with relevant laws and avoid unwanted governmental and public scrutiny.

Sports leagues and teams proactively engaging in SRS can help craft a more positive relationship with constituencies, including local and state governments and communities. ${ }^{10}$ Good relationships with local and state governments can have tangible benefits like promoting public contributions in the form of bonds and tax credits for building new stadia. ${ }^{11}$

\section{Contract Relations}

An example of U.S. law operating as a floor that prevents irresponsible behavioras opposed to requiring outstanding behavior-is morality clauses in athlete contracts, which historically required that athletes adhere to basic expectations for being a good citizen. ${ }^{12}$ Now, the corporate world-sports included-is experiencing a paradigm shift holding industry players accountable for more than producing high-quality products and making money for shareholders. Accordingly, there are new relevant legal requirements that speak to a higher level of social responsibility or morality. Many player contracts set requirements for positive action like participation in disease awareness campaigns and contributions to charities. Sports entities, industry sponsors, and nonprofits contract together to improve public welfare on a regular basis. It might be argued that what was once outstanding behavior is now expected behavior when it comes to empowered sports entities and their obligations to their employees and their communities.

\section{The $C B A$}

Because collective bargaining agreements are the product of negotiations between the most significant stakeholders in a professional sport, these are good indicators of the extent to which social responsibility is prioritized by a league. Currently, SRS is embodied in CBAs to varying degrees across leagues. At minimum, the negotiations between most leagues and players unions result in the incorporation of some requirements for public appearances and expectations for acceptable behavior into CBAs. The Major League Soccer (MLS) CBA requires players to attend various events, including some public service or charitable in

\footnotetext{
${ }_{10}$ See Yuhei Inoue, Aubrey Kent, \& Seoki Lee, CSR and the Bottom Line: Analyzing the Link Between CSR and Financial Performance for Professional Teams, 25 Journal of Sport MANAGeMENT 531, 535 (2011) (citing Babiak \& Wolfe). https://doi.org/10.1123/jsm.25.6.531

11 See Editorial Board, Gov. Jay Nixon's Go-It-Alone Approach Wrong Way on St. Louis Stadium Deal, The Kansas City Star (December 14, 2015). Available at http://www.kansascity.com/opinion/ editorials/article $49755080 \mathrm{html}$ (The St. Louis stadium debate is an example of how trust between key political leaders and sports leagues can help proposals take shape).

12 See Carrie Moser, Penalties, Fouls, and Errors: Professional Athletes and Violence Against Women, 11 Sports LaWyers Journal 69, 75 (2005).
} 
nature. ${ }^{13}$ Some go further; for example, the Major League Baseball (MLB) CBA describes expectations for the amount of a player's salary that can be required for contribution to a team's charitable foundation as per the Uniform Player Contract. ${ }^{14}$ The National Basketball Association (NBA) CBA mandates player attendance at anti-gambling and HIV awareness workshops, ensures that money collected from player fines is channeled into charities, regulates player ownership of weapons, and sets guidelines for player behavior both on and off court. ${ }^{15}$ The examples from the NBA agreement demonstrate both its commitment to protecting the well-being of its athlete employees, and commitment to the broader community. The integration of each of these clauses was likely the result of lengthy negotiations with the players' union, and represents the extent to which social responsibility is woven into the ethos of the NBA.

\section{Contracts governing teams/league/nonprofit partnerships}

One of the most significant forms of social responsibility engagement for teams and leagues is partnering with nonprofit entities. By contributing financial resources and brand identity, a team or league can help a nonprofit expand its reach or improve its performance. The team or league can then leverage its association with the public interest organization to improve its image in the eyes of stakeholders, satisfy its responsibility to its community, improve loyalty among fans, and potentially bring in new fans who care about the nonprofit's mission. If successful, this collaboration can also contribute positively to the sport organization's bottom line without being driven by profit motive. These sport/nonprofit collaborations must be governed by contracts that stipulate the terms of the relationship. Often, these contracts will require a payment transfer from the sports entity to the nonprofit, ostensibly in exchange for advertisement of the relationship. ${ }^{16}$ The contract might also provide for the engagement of team/ league employees or athletes directly with the nonprofit, in the form of public appearances or perhaps in the direct provision of services. ${ }^{17}$

As these kinds of partnerships have become standard across professional sports, the cache of simply engaging with a nonprofit is limited. Fans are wary of inauthentic social responsibility efforts, performed for their symbolic value or to respond to a public relations crisis. Accordingly, each sport organization must find the "right" collaboration and leverage it in the most effective way to actually increase fan loyalty, reputation improvement among stakeholders, and return on investment. This has several implications for the actual contractual agreement. First, it likely means shorter term initial arrangements to gauge the impact of the

\footnotetext{
13 MLS CBA, 2004-2010 Collective Bargaining Agreement. Available at https://ipmall.law.unh.edu/ sites/default/files/hosted_resources/SportsEntLaw_Institute/2004MLS_MLSPA_CBA.pdf

14 MLB CBA, 2012-2016 Basic Agreement. Available at https://ipmall.law.unh.edu/sites/default/ files/hosted resources/SportsEntLaw Institute/2012MLB MLBPA CBA.pdf

15 NBA CBA, 2011 Collective Bargaining Agreement. Available at http://nbpa.com/cba/.

16 See Joseph Galaskiewicz \& Michelle Sinclair Colman, Collaboration Between Corporations and Nonprofit Organizations, 2 The Nonprofit Sector: A Research Handbook 180 (2006).

17 Id.
} 
relationship. Hypothetically, if after one year, Major League Lacrosse discovers that its fans have no awareness or appreciation for its relationship with a nonprofit fighting malaria in Kenya, then it will want to reserve the right to terminate the relationship. Second, it likely means closer interaction between both parties. To demonstrate that the partnership is more than symbolic, leagues and teams often want their athletes and other employees to engage directly with the nonprofit either at public appearances (benefit dinners, press releases, etc.) or in the direct provision of services (such as building houses, reading to children, or cleaning up the environment). ${ }^{18}$ It might also require representatives from the nonprofit to appear at games or league events to publicize its achievements. Third, the sports entity might hold its nonprofit accountable for achieving its mission. Beyond an exchange of money for promotional rights, the contract might require the nonprofit to provide regular reports of its progress and direct accounting of how the league or team's money has been spent.

The evolution of the sports entity/nonprofit contract reflects and reinforces the team or league's commitment to social responsibility. These contractual relationships can be time and resource intensive, and are likely one component of the social responsibility programming of a given professional sport organization. It has thus behooved senior leadership to commit sufficient personnel and resources to manage this activity portfolio.

\section{Leadership}

The extent to which professional sports leadership has embraced the importance of social responsibility bodes well for the cultural development of their organizations and the sports industry. The drive to "do the right thing" emanates from senior leadership and motivates leagues to engage in SRS. Most league leadership understands that SRS efforts are increasingly necessary to keep community-minded fans engaged. These sentiments align with the view that "good corporate ethics is now understood to reduce the cost of business through establishing trust among stakeholders, improved team efficiency, and preservation of social capital." 19 Consensus among league and team leaders will be a key asset in identifying sports-wide social responsibility standards for operation and principles for improvement.

Senior leadership's commitment to social responsibility has taken many forms and has resulted in structural change on the part of leagues. In several major leagues that have developed departments and personnel specifically reserved for social responsibility, the leadership of each of these departments report directly to the commissioner and other senior executives of their respective leagues. ${ }^{20}$

Even in leagues that do not have dedicated social responsibility departments, it is clear that the drive for social responsibility comes from the highest levels of the organization. For instance, one professional sport organization's impetus

\footnotetext{
18 NYU Professional League Interview Nos. 1 and 2, 2016. Transcripts on file with authors.

19 Matthew Walker \& Aubrey Kent, Do Fans Care? Assessing the Influence of Corporate Social Responsibility on Consumer Attitudes in the Sport Industry, 23 Journal of SPORT MANAGEMENT, 742, 749 (2009). https://doi.org/10.1123/jsm.23.6.743

20 NYU Professional League Interview No. 2, 2016. Transcript on file with authors.
} 
for engaging with the community comes directly from the founding family, and its foundation's philanthropic focus on improving the health of children is set directly by one of its chairpersons. ${ }^{21}$ Leadership's commitment to social responsibility will carry the strongest guarantee of implementing impactful programs that resonate with stakeholders and benefit the sports industry.

\section{Reasons to Engage in SRS}

\section{Labor Relations}

Social responsibility is important to employees. Contemporary management literature suggests that prudent companies can leverage this importance to foster better labor relations. Engagement goes beyond simply motivating workers or obtaining adequate performance. Instead, it encompasses a commitment to and belief in the organization and its values. When employees believe in their company's mission and respect its policies, they are likely motivated to work harder to help the organization reach its goals.

In a white paper for Mandrake, Rob Gross surveyed contemporary management literature to find that "less than one-third of employees are engaged, and that two of five employees would not recommend their employer as a place to work" and another $25 \%$ are just "showing up to collect a paycheque." 22

Polling data shows a positive correlation between high levels of employee engagement and company profitability with lesser levels of employee turnover. ${ }^{23}$ Given the high costs of replacing employees, ${ }^{24}$ there is a clear organizational incentive for companies to invest in activities that motivate their workforce.

Growing research suggests that social responsibility initiatives can promote employee engagement. Employees who are satisfied with their employer's commitment to social responsibility tend to demonstrate high levels of engagement and connectedness with their employer. ${ }^{25}$ Sixty-two percent of millennials (those born between 1981 and 1996) claim to be willing to take a pay cut to work for a "responsible" company. ${ }^{26}$

Teams and leagues understand that SRS efforts play a key role in motivating workers and can help define their organizational character. For instance, one prominent U.S. league proudly points out that $98 \%$ of its employees believe that

\footnotetext{
21 NYU Professional League Interview No. 3, 2016. Transcript on file with authors.

22 Rob Gross, Corporate Social Responsibility and Employee Engagement: Making the Connection, White Paper for Mandrake, 2 (2011). Available at http://www.mandrake.ca/bill/images/corporate_responsibility_white_paper.pdf.

${ }^{23}$ Id. at 4 (describing polls from Gallup, Towers Perrin, and International Survey Research, which claim a strong correlation between employee engagement and company profitability).

24 Id. at 5 (explaining that as much as one to three times his or her annual salary, with the average company losing \$1 million with every 10 professional employees who leave the organization).

25 Id. at 12.

26 See Cone Communications, Milennial CSR Study, 1 (2015). Available at http://www.conecomm. com/research-blog/2015-cone-communications-millennial-csr-study
} 
they are a leader in SRS and argues that the robust employee volunteer program involves the entire organizational family and helps "people feel connected." 27

Commitment to SRS creates trust and strengthens relationships between leagues, teams, and athletes. Regardless of business relations status, these three entities continuously work together on socially responsible initiatives, which arguably serve as a basis for constant communication and as a platform for shared values.

One prominent U.S. league notes that its structural reorganization with a clear focus on community and player programs resulted from a desire to "develop those relationships, to frankly, develop a better trust with them in terms of what we needed them to do to help grow the business." ${ }^{28}$ An SRS leader in another league states that relations with the players' association remains strong with regard to SRS and that athletes are keen to cooperate with the league on SRS due to the "goodness of their heart." ${ }^{29}$ Yet another points to one of its team superstars who gifted several million dollars to a local children's hospital as an example of athletes themselves spearheading such cultural shifts towards increased SRS. ${ }^{30}$

SRS-related relations are also persistent and durable. One league executive notes that even while relationships with the players' association suffered, there was always close cooperation with regard to SRS. The executive pointed to its long-running campaign to fight cancer as a program that has gone back at least 20 years and has endured "through the good years, through the lockouts, through everything." 31 This shows that SRS can serve as a basis for constant communication and as a platform for shared values.

In leagues where athletes are not employees but independent contractors, interviews revealed that that they elected to engage in SRS on their own and that such activities positively influenced the work environment for other employees. ${ }^{32}$

Employees of sports leagues are the growing embodiment of a cultural shift towards increased social responsibility spurring higher engagement and productivity.

\section{Economics}

Beyond the moral duty born by those empowered in the professional sports world to improve their communities, and the legal requirement for sports to operate inclusively, significant benefits can be derived from meeting these expectations. Leagues, teams, and players that engage in social responsibility efforts can enhance their businesses and brands.

Satisfying the public's expectation with regard to SRS will likely translate into the fulfillment of economic goals. As noted by Godfrey, engaging in SRS can promote cause-related marketing where "firms that create social gains realize

\footnotetext{
27 NYU Professional League Interview No. 1, 2016. Transcript on file with authors.

28 Id.

29 NYU Professional League Interview No. 2, 2016. Transcript on file with authors.

30 NYU Professional League Interview No. 4, 2016. Transcript on file with authors.

31 Id.

32 NYU Professional League Interviews Nos. 3 and 5, 2016. Transcripts on file with authors.
} 
cash value in terms of either increased purchase by morally-conscious customers (or conversely the willingness of these customers to bear higher prices) or through lower costs of production." 33 This theory is supported by research suggesting an increasing correlation between social responsibility and market actions.

For instance, as it relates to millennials, a 2015 Cone Communications Millennial CSR Study of more than 1,000 Americans shows that social responsibility efforts can affect what products millennials purchase, how millennials discuss corporations via social media, and for which companies they choose to work.

With regard to basing consumption choices on CSR, $87 \%$ of millennials will purchase a product with a social or environmental benefit, $82 \%$ will tell friends and family about CSR efforts, $70 \%$ will voice opinions to a company about its CSR efforts, and 74\% will volunteer for a cause supported by a company they trust. Furthermore, $70 \%$ of millennials are prepared to pay more for a product based on CSR. In each of these cases, millennial attitudes surpass that of the U.S. average. ${ }^{34}$

Not only do millennials consume differently, but they are also more likely to discuss CSR efforts online. They have a unique ability to amplify their voice by directly addressing or engaging with companies on social and environmental issues. Two-thirds of millennials have done so, as opposed to the $53 \%$ U.S. average. With regard to CSR effort, this engagement can be used to share positive information (38\%), negative information (26\%), directly communicate with companies on issues (18\%), or even to contribute directly to a company-led effort $(17 \%){ }^{35}$

This insight into a growing market segment shows that social responsibility can have a tangible effect on the bottom line of leagues and teams. A league or team's reputation and the reputation of their players as brand ambassadors play a role in fan acquisition. ${ }^{36}$ Fan loyalties and consumption habits are affected by the sport's social responsibility programming. In focus groups, fans explained that they were more likely to attend games if proceeds went to causes they appreciated, and that players' off-field behavior would influence their decision to buy branded merchandise. ${ }^{37}$ Evidence suggests that effective investment in SRS might strengthen existing fan relations, and assist in expanding the fan base. In newer leagues, this type of positive engagement is particularly important as they fight for new audiences. ${ }^{38}$

SRS is also crucial for engaging sponsors. Often, marketing sponsors base

\footnotetext{
33 See Paul Godfrey, Corporate Social Responsibility in Sport: An Overview and Key Issues, 23 Journal of Sport MANAgement, 698, 706 (2009). https://doi.org/10.1123/jsm.23.6.698

34 See Cone Communications, supra note 26 , at 1.

35 Id. at $1-2$.

36 NYU Professional League Interview No. 3, 2016. Transcript on file with authors. NBA Interview.

37 NYU Focus Groups hosted by Fondulas Strategic Research, LLC, Jan. 13, 2016, Chicago, Illinois. Transcripts on file with authors.

38 See Darren Heitner, How Major League Soccer Is Closing The Gap With The Big Four, ForBes (Dec. 22, 2015). Available at http://www.forbes.com/sites/darrenheitner/2015/12/22/how-majorleague-soccer-is-closing-the-gap-with-the-big-four/
} 
their sports relationships in part on the team or league's social responsibility activity. As noted by Babiak and Wolfe, this is due to the fact that "corporate sponsors are not only frequently involved in CSR themselves, but are increasingly incorporating community outreach efforts as part of their sponsorship packages with professional sports teams." ${ }^{39}$ A senior league executive explained that industry partners have extended sponsorship agreements based specifically on the goodwill generated by the league's wholesome image, fostered in part through SRS. Name brand sponsors seem to believe that there is less risk in long-term associations with leagues invested in communities through SRS and that they will benefit from the resulting halo effect. ${ }^{40}$ At the same time, it is reasonable for sponsors to exercise great caution when choosing a league to sponsor. A recent global poll suggests that only $32 \%$ of Americans surveyed believe the corporate sponsor of a league is not at least somewhat responsible when a scandal occurs in that league. ${ }^{41}$

League or team SRS objectives must be coordinated with partner objectives. Teams might have their own partnerships that conflict or compete with a league's proposed partnership. The success of a given league social responsibility program can be limited or strengthened by the extent to which the interests of each involved party are considered before agreements are made. Carefully crafted programs with team and sponsor support carry quantifiable economic benefits. Tracking economic gains made possible by SRS programs can assist sport organizations in making optimal future SRS decisions.

SRS also creates positive media attention, which can generate economic gains. All interviewed league representatives described public relations benefits derived from SRS programs. The effects of SRS media coverage on league image can be measured through pre- and post-program awareness studies ${ }^{42}$ Evidence suggests that programs with a measureable impact on fans' immediate communities have the strongest positive influence on fan perception. Because athletes represent their teams and teams represent their leagues, the social responsibility efforts of the athlete affect the team, and those of the team affect the league. Athletes that are accessible and engaged with the community reap direct personal benefits for their personal brands, and reflect well on their team and their league. It is likely that such outstanding athlete-citizens play a strong role in fan acquisition and retention.

A professional sport organization's SRS initiatives can create value in terms of workforce safety, health, and morale, and can generate both direct and indirect economic gains. But this value is largely mediated by the authenticity of the SRS effort.

\footnotetext{
39 See Babiak \& Wolfe, supra note 1, at 728.

40 NYU Professional League Interview No. 5, 2016. Transcript on file with authors.

41 IPSOS, Guilty by Association, Ipsos Socialogue, global poll conducted Oct. 2015. Data on file with authors.

42 See Chang-Wook Jung, The Influence of Professional Sports Team's Corporate Social Responsibility (CSR) on Team Image, Team Identification, and Team Loyalty, Doctoral Thesis Submission St. Thomas University, 2 (2012). Available at https://search.proquest.com/ docview/1266851225?pq-origsite=gscholar.
} 


\section{Conclusion}

At its best, SRS represents compatibility between the business motives of a sport organization and the well-being of its community - where doing good, and doing good business, meet. Achieving this end requires a genuine commitment that goes beyond symbolic investment in a social responsibility platform. More sports fans are socially concerned citizens who know the difference between a team or league that follows the SRS trend and another that is seriously engaged in public improvement. Authentic social responsibility efforts must be aligned with the values and identity of an organization, and must have measurable impact on the community. Identifying the right investments requires that a sport organization understands its own brand, the interests of its fans, and the needs of the community, and to strategically engage with government, nonprofit organizations, corporate sponsors, and the general public toward effective service. The most effective SRS efforts likely depend upon a commitment to measurement and evaluation of: (1) the degree and type of an organization's investments; (2) the actual impact of each social responsibility initiative; and (3) the return on investment of that initiative. This commitment can be reflected and reinforced through organizational structure, by establishing an internal team that sits outside public relations or marketing departments and is committed specifically to social responsibility, through policies for how initiatives are implemented and how public interest partners are chosen, and through contracts that hold actors responsible for demonstrating the effectiveness of their work. 